TITLE:

\title{
Applicability of a spatial computable general equilibrium model to assess the short-term economic impact of natural disasters
}

\author{
$\operatorname{AUTHOR}(S)$ :
}

Kajitani, Yoshio; Tatano, Hirokazu

\section{CITATION:}

Kajitani, Yoshio ... [et al]. Applicability of a spatial computable general equilibrium model to assess the short-term economic impact of natural disasters. Economic Systems Research 2018, 30(3): 289-312

ISSUE DATE:

2018

URL:

http://hdl.handle.net/2433/241267

\section{RIGHT:}

This is an Accepted Manuscript of an article published by Taylor \& Francis in Economic Systems Research on 28 September 2017, available online: http://www.tandfonline.com/10.1080/09535314.2017.1369010.; この論文は出版社版 でありません。引用の際には出版社版をご確認ざ利用ください。; This is not the published version. Please cite only the published version. 


\title{
APPLICABILITY OF A SPATIAL COMPUTABLE GENERAL EQUILIBRIUM MODEL TO ASSESS THE SHORT-TERM ECONOMIC IMPACT OF NATURAL DISASTERS
}

\author{
YOSHIO KAJITANI ${ }^{*}$ and HIROKAZU TATANO ${ }^{\mathrm{b}}$

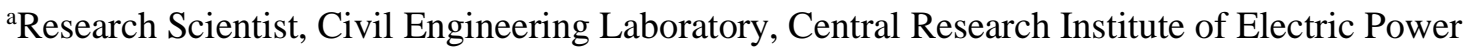 \\ Industry, 1646 Abiko, Abiko City, Chiba, 2701194, Japan

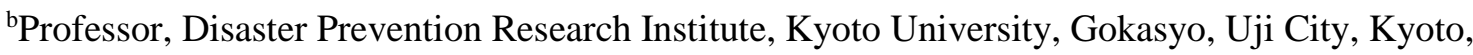 \\ 6110011, Japan
}

\begin{abstract}
Computable general equilibrium (CGE) models have been widely used to assess the economic impact of natural disasters, but the models have not been fully validated by applying them to real disasters. This study focuses on validating a model for use in a short-run case in which the functional recovery of infrastructure and businesses occurred on a time scale of a few months. A special attempt is made to determine the parameter values of elasticity of substitutions, which play an important role in the effect on supply chains. In this study, a spatial CGE model, in which Japan is divided into nine regions, is constructed and applied to the case of the 2011 Great East Japan Earthquake and Tsunami. Through this application, the best estimates of the elasticity parameters generated relatively consistent estimates of production change compared with the observed change, both in severely affected regions and in other regions.
\end{abstract}

Keywords: Economic Impact, Computable General Equilibrium Model, Supply-chain Damage, Elasticity of Substitution

This is an Accepted Manuscript of an article published by Taylor \& Francis in Economic Systems Research on 28 Sep 2017, available online: https://www.tandfonline.com/doi/full/10.1080/09535314.2017.1369010. 


\section{Introduction}

Estimating the economic impact of damage caused by natural disasters is essential for understanding disaster risks quantitatively. This is also true for the potential effects of pre-disaster investments (e.g., retrofitting infrastructure) and the post-disaster recovery strategies for infrastructure and businesses (e.g., recovery resource allocation). Accordingly, theoretical and empirical improvements have been made in the methods used for such estimates, and diverse analytical methods are available (see, e.g., Okuyama and Chang, 2004; Okuyama and Santos, 2014). Among them, computable general equilibrium (CGE) models can estimate economic loss, and, hence, have enhanced their popularity for estimating economic impacts of damage. CGE models have the advantage that they describe economic structure in detail and can be applied flexibly to complex real-world economies. This is done by changing functional forms of production, altering key model parameters, and varying the form of macroeconomic-closure. Thus, CGE models can analyze economies in complex disasters.

Indeed, Rose and Liao (2005) discuss the effectiveness of a CGE model for analyzing economic resilience in disaster impact assessments. They interpret the optimization characteristics of the CGE models as economic resilience. In addition, they reflect disaster mitigation behaviors, such as the conservation of water, in a production function with constant elasticity of substitution (CES). The use of CGE models for disaster impact analysis can be extended by allowing changes in transportation infrastructure to affect interregional trade flows. For example, Tatano and Tsuchiya (2008) developed a spatial CGE (SCGE) model to analyze the effect of transportation network damage on multiregional economies.

Still, the applicability of CGE models to disaster impact analysis has been questioned. Greenberg et al. (2007) suggest that the use of the CGE model may not be perfectly grounded for use in disaster assessments since in such situations "the assumption that consumers and producers optimize is debatable." That is, they might derive over-optimal results in the caser of disaster impact analysis. Citing Partridge and Rickman (1998), Greenberg et al. (2007) also note that "a chief criticism leveled at CGE models is that they rely on external sources for some of the elasticity values required during their calibration." In essence, the parameters for the elasticity of substitution need refinement for both disaster and non-disaster cases.

Optimization and substitution parameter problems can magnify depending on the time scale of the analysis. CGE models can be applied to derive findings for both the "short-run" and "long-run." Typically the short run is a relatively rigid setting, with restrictions on labor and capital movements (partial optimization). To assure rigidity, elasticities with lower magnitudes are employed to ensure low substitutability. Elasticities of larger value as well as additional optimization behaviors (weaker assumptions on labor and capital mobility) are applied to enable long-run cases. Still, while infrastructure and businesses undergo tentative recovery, the equilibria of economies, which are assumed in a long-run model, are not typically attained. Thus, short-run CGE models are more plausible for the case of disasters; however, the forecasting capabilities of such models have not been examined. ${ }^{1}$

Against this backdrop, we examine the applicability of a short-run CGE model using a case study of an actual disaster. In particular, we focus on plausible elasticity of substitution parameters for interregional imports and exports. For this purpose, we construct and apply an SCGE model using different elasticities of substitution to the case of the Great East Japan Earthquake in 2011. We investigate the performance of several CGE simulations by comparing the estimated monthly industry

1 A "long-run" study, such as the analysis of the negative regional impact of debts incurred by local governments and households, is also critical in estimating longer-term impacts. However, this type of study is beyond the scope of this paper. 
production against equivalent observed values. We find that some specific interregional trade substitution parameters work reasonably well in the case of short-run disaster impact analysis.

\section{Review of Previous Work}

Numerous studies have been conducted on models that estimate the economic effects of disasters. Generally, economic damage from disasters is classified as a stock or flow. As stock, the damage is the economic value of accumulated physical and financial capital that is damaged by a disaster. In contrast, as a flow, damage represents the loss of economic outputs, such as the production of goods, provision of services, and the creation of value added over a certain interval.

Analyzing flow damage is more difficult because of the complex, time-dependent factors affecting economic output in a disaster. First, in the event of a disaster, production systems are often damaged or experience reduced capacity due to labor and capital shortages and disruption to critical infrastructure (e.g., electricity, water, and gas). In addition, damage to transportation networks can increase transportation costs or disrupt the flow of goods and services. In the case of a disaster, impacts are not limited to areas that experience physical damage; they can spill over into other regions via supply chains. These factors are all on the production side. But changes can also occur on the demand side. In the wake of a disaster, people can change their life patterns such that both general consumer demand and the propensity to consume certain goods are affected.

To estimate the total flow losses resulting from these complex economic activities, inputoutput (IO) and CGE models have been employed (Okuyama and Santos, 2014). Specifically, CGE models are suitable for analyzing the combined supply- and demand-side effects mentioned above because the model generically describes producer and consumer behaviors. Conversely, because an ordinary input-output model is demand-driven, the magnitude of production must be determined by the magnitude of final demand. There is also a supply-driven input-output model (Ghosh, 1958), although, as noted by Oosterhaven (1988), there are problems with how that model's assumptions conform to reality. In both cases, there must be more discussion about how to incorporate both supply-driven and demand-driven effects, which simultaneously occur during a disaster.

For example, Hallegatte (2008) developed the input-output model with a plausible rationing scheme for demand in a disaster situation. In his model, priority is given to meet demands under the production capacity constraints, such that business-to-business transactions outweigh business-tohousehold transactions. Oosterhaven and Bouwmeester (2016) employ the theory of minimum information gain (maximum entropy), so to enable their model to reflect business behavior, which tries to recover normal operations in as much as possible, and to avoid case-specific assumptions about the reactions of the upstreamness and downstreamness of industries. Koks and Thissen (2016) introduced an IO model with the idea of inefficient production. In their model, interregional imports are substituted among regions, and production losses in the physically damaged region are substituted by production from other regions to meet final demand. The cost of production, therefore, increases in many regions due to the use of less-efficient production technologies.

Thus, several studies have attempted to fit an IO model to apply to the disaster case. It is noteworthy that the model in Oosterhaven, and Bouwmeester (2016, p. 585) achieves a large benefit because it "keep[s] the simplicity of [an] (IR)IO model but [is] arranged with the plausibility of [a] CGE model". It should be understood however that IO models are a special case of CGE models. Thus, both approaches (either IO-based models with some altered coefficients or CGE-based models with some fixed/rigid coefficients) are necessary.

The application of CGE models to disaster impact analysis has gained increasing attention over the past 25 years. Rose and Guha (2004) noted that the advantages of CGE models have been highlighted 
since the early 1990s, but the applications of the model have been "limited to simple stylized examples." Rose and Guha also classified the configurations of CGE models for disaster impact analysis in terms of time scales. For example, in a very short-run case, in which the period is projected to last less than seven days, "A CGE model is appropriate here but with input and import elasticities set very low (probably less than 0.1)." Therefore, IO models that have a fixed input and import become valid in periods of such short duration.

In their classification, our later case study ranges in the martial law case (less than 30 days), in which a central government can control an economy, or in the short-run case (less than 6 months), in which input substitutions or other resiliency measures occur. In the short-run case, they assume the input elasticities are also low, generally less than 1, if the transportation networks are extensively damaged. These discussions are critical for constructing appropriate models on different time scales; however, to the best of our knowledge, no validation has been conducted through a case study of a real disaster. Our current case study is limited to monthly analysis because the observed data (production index) for the validation of estimated production are available only in this time scale. Moreover, this case study is quite specific (large-scale disaster in Japan); its results cannot be generalized for other disaster cases at this stage. Rather, consider this study a starting point for accumulating case results, which is necessary to provide information on the reliability of disaster impact analysis to policy makers. The case study in this paper provides one set of reference substitution parameter values in a disaster that should be tested in other case studies in the future.

In fact, it is challenging to validate CGE and also IO models on a monthly scale. One reason is that some of the parameters in a CGE model, such as the input-output coefficients, must be estimated based on yearly (or less frequent) benchmark data sets. In the short-run, inputs may be conserved and inventories can be fully utilized to mitigate tentative production shocks, which constitute a departure from the average production pattern in a year. Therefore, if the time scale of the analysis becomes shorter, we can infer that modelers should be less able to estimate damages using a standard CGE model. Our model, described in Section 3, encounters this inherent drawback pertaining to the time scale even when we enable it with several short-run settings. It might be possible to overcome this time-scale problem by incorporating several proposals from previous studies on disaster impact analysis. For example, to describe supply-side adaptation behaviors following a disaster, Okuyama et al. (2004) employed the sequential interindustry model (SIM) ${ }^{2}$ which extends an IO model with a time-phased production system (production chronology).

The disaster-specific settings of a CGE model are also found in Tatano and Tsuchiya (2008). They applied a CGE model to the case of an earthquake disaster using putty-clay assumptions. ${ }^{3}$ In the analysis, production factors, normally capital and labor, are assumed substitutable and mobile before an event, and they are used to formulate the optimal production capacity. Following the disaster, the substitutability of factors is assumed to be low in the short run. Putty-clay models are typically used to consider economic rigidity. Atkeson and Kahoe (1999) observed that how capital formation that is affected by electricity price is more consistent with the estimates of the putty-clay model than with those of the standard putty-putty model.

Decreases in consumption and decreases in income might not be directly linked. Changes in consumer behavior due to psychological factors emanating from a disaster have not yet been studied

\footnotetext{
2 According to Romanof and Levine (1986), a series of developments (publications) on SIM began since 1977. In their study, capacity limitations and inventory are incorporated in a time-phased production system.

${ }^{3}$ Putty-clay models assume different substitutability of production factors before and after the capital is installed. According to Atkeson and Kahoe (1999), the model was initially set up by Johansen (1959). 
sufficiently. People might refrain from consuming superior goods and might hoard scarce goods when faced with a disaster. Unfortunately, psychological elements are practically nonexistent in CGE model analysis; so limited research on such matters exists, although Giesecke et al. (2012) consider psychological effects of terrorist attacks.

In a CGE model for disaster impact analysis, price variables must be treated carefully. There are inconsistencies between the model and reality concerning price changes after a disaster has occurred. For example, Cavallo et al. (2013) investigated shortages and prices of goods in supermarkets for the 2011 Great East Japan Earthquake and the 2010 Chilean Earthquake. Although the number of items at supermarkets declined by $17 \%$ in Japan and $32 \%$ in Chile, from which we can assume that at least some quantifiable shortage occurred, prices did not change for a while after the disasters (i.e., they were "sticky") and generally followed the pre-disaster inflationary (Chile) and deflationary (Japan) trends. Price increases in Japan occurred in July 2011, more than four months after the disaster. Supply-demand balance is not achieved by a price mechanism immediately after a real disaster; in this respect, IO should be preferred for such analysis.

As explained by Greenberg et al. (2007), it is more natural to interpret price variables as proxy indicators of the scarcity of goods, which is not linked to the actual price of goods. In other words, the role of prices in the CGE model determine the allocation of scarce goods and services (i.e., rationing). Therefore, if the real allocation rule is centrally planned and is independent of scarcity, it is difficult to apply the CGE model to a disaster economy. In contrast, in cases when the supply of goods exceeds demand at the original price, whether to allocate the surplus of goods by decreasing the prices is debatable. It may be more appropriate to believe that a goods or production factor surplus could be generated instead of decreasing prices during a disaster. This approach is similar to a discussion of disequilibrium in a short-run study; one method for determining factor surplus in the CGE model is changing a closure rule to employ downward price rigidity, as seen in Section $3^{4}$.

Validating CGE models and disaster impact models in general is challenging, although doing so is required to prove the viability of their practical use. Many types of policy analyses use various CGE models, but few determined how the CGE model gauge predicted results against actual data. Dixon and Rimmer (2013) discuss the validation of CGE models and note that, in addition to the target policy, other policies and shocks that affect the real economy are reasons for verification failure. Interestingly, predicted production of 500 industries in the United States from a dynamic CGE model outperformed those from simple trend extensions in terms of the absolute differences from actual figures. The dynamic CGE model parameters were calibrated using data from 1992-1997 and production was predicted for 1998-2005. Several other studies have similarly attempted to verify CGE models, none yet have been verified for the case of disasters.

Promising configurations of CGE models for disaster impact analysis have been discussed in this section, such as the size of the substitution parameter, putty-clay assumptions, and the closure rule. To understand the implications of these model configurations and to confirm the performance of CGE models, it is necessary to validate CGE models through case studies of actual disasters. In particular, sensitivity analyses are required for various model settings and parameter values.

\section{Outline of the Model}

4 The downward rigidity of the price of labor is employed by Rose and Guha (2004) to model the decrease in labor inputs. 


\subsection{The Economy during a Natural Disaster and Short-run Settings of CGE Models}

As discussed in the previous section, our focus is on short-term flow losses (several weeks or months), in which CGE models with several constraints can be valid. For example, although prices might be fixed, capital is likely to become idle instead of being fully allocated and utilized across sectors and regions. The difference between an economy during normal and disaster periods should remain as small as possible because continuous recovery activities are likely to restore original economic conditions to most sectors rapidly. Because many businesses expect the economy return to the original conditions, the adjustment to a tentative gap between supply and demand is expected to be slow in the short-run after a disaster.

Such a mechanism can be imbedded in a short-run CGE model. Bourguignon et al. (1983) claim, "Most of the existing models, for instance, are built along neo-classical assumptions, which seem quite appropriate in the long-run-i.e., capital-labor substitution, full employment, market-clearing prices, etc.- - but might be somewhat inadequate in the short- or medium run," and they examine a CGE model that combines both short- and long-run characteristics based on the basic structure proposed by Taylor and Lysy (1979). ${ }^{5}$ In their short-run model, they introduce putty-clay production functions, unemployment with a relationship to nominal wage, and price rigidities. Such short-run assumptions can be appropriate for disaster impact analysis because the series of shocks, including recovery activities, prevents the effective adjustment of resources post-disaster.

As described in the mathematical formulae in a later section, typical short-run settings are employed that describe economic effects for several months after a disaster. These settings encompass immobile capital and labor among regions and sectors, no income change in the household sectors, ${ }^{6}$ and the facilitation of slacked demand for labor as opposed to forcing full employment.

\subsection{Elasticity of Substitution Parameters for the Assessment of Supply-chain Effects}

When estimating short-term effects low values for elasticities of substitution are typically used; but how low should they go? In a CGE model, the extent of supply-chain effects can be analyzed by estimating the elasticity of substitution of a good across regions. If the substitution parameter is small, then domestic sectors likely reduce their production if they use inputs from damaged sectors.

In the following analysis, the basic parameters for the elasticity of substitution, as estimated by Koike et al. (2013), are used for the baseline dataset. This baseline is tailored to Japanese interregional trade. Koike et al. (2013) generate parameter values from input-output tables and the national census of commodity flows, which was conducted quinquennially from 1980 to 2005. The estimates are relatively low (less than 1 for most of the sectors), even for the long-run in Japan. As a main objective of this study, a sensitivity analysis of the parameter values is performed to find a parameter value that can explain the case of real disasters.

\subsection{Production Capacity Loss Rate for Setting External Shocks to Production Systems}

In the ordinary application of CGE models to disaster impact analysis, shocks to production systems are set by decreasing capital stocks. These datasets are usually provided by local or central governments because they are essential for estimating recovery costs. But, particularly in short-run conditions, the production capacity is not determined by the cost of damaged stocks but rather by the functionality of the production systems. The functionality of production systems can be easily lost without any costly damage, for example, by the dislocation of production machinery.

\footnotetext{
5 In fact, Taylor and Lysy (1979) investigated the effects on income redistribution via a one-sector model that is characterized by fixed capital, exogenous investments, and nominal changes in prime cost (Keynesian); they demonstrated that the model produces relatively insensitive functional income distribution.

6 This type of external setting of final demand is viewed as a type of Keynesian closure by Robinson (1989). 6
} 
We use the production capacity loss rates (PCLRs) estimated by Kajitani and Tatano (2014) are used. The PCLRs are derived from the vulnerability and resilience characteristics of various industrial sectors considering the extent of ground motion and tsunami hazard during the Great East Japan Earthquake and from the infrastructure disruption and evacuation that occurred because of the Fukushima Daiichi nuclear disaster. We have already demonstrated that the estimated PCLRs concur with the observed IIP. The conversion of the PCLRs to the shocks of hypothetical stock and labor damage for CGE inputs is explained in Section 4.

PCLR is suitable for describing maximum production and has a small relationship with the actual recovery costs because costless recovery activities (e.g., cleaning up and relocation of machinery) are dominant during earlier periods after a disaster. However, if the recovery investments increase over time (e.g., via the reconstruction of buildings), it is necessary to incorporate the cost of recovery to properly estimate the flow losses. Our case study does not include the recovery investment, but such investments should be considered in a longer-term analysis.

\subsection{SCGE Model Considering Economic Activities during a Disaster}

Several models that consider various assumptions during a disaster are briefly explained here. An introduction to the basic structures and applications of CGE models is available in many textbooks (e.g., Shoven and Whalley, 1992; Hertel, 1997; and Dixon and Jorgenson, 2013); therefore, we do not repeat such details here. The relevant datasets, such as input-output tables and elasticity of substitutions, have also been estimated and updated by many organizations and individual researchers (e.g., Badri and Walmsley, 2008). For the CGE model, this study uses a simple structure as described by Ueda (2010). It eliminates government as a separate final demand sector and combines it with households. This basic model allows the study to focus on analyzing the distribution of available resources and goods among domestic industrial and household sectors and yet avoids some of the black-box characteristics inherent to some more-complex CGE models. The parameters and variables that must be clearly identified in the equations as being either for the normal or disaster cases are suffixed by 0 (normal case) and 1 (disaster case). The equations without a 0 or 1 suffix are assumed identical for the normal and disaster cases.

\section{1) Industrial sector (firms)}

Firms are assumed to have the production structures shown in Figure 1 during both disaster and normal periods ${ }^{7}$. Domestic final product $X d_{j}^{s}$ in the second layer in Figure 1 is determined by inputting composite goods from each sector and value added based on a Leontief production function given by

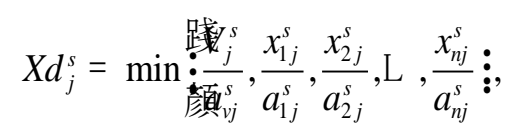

where $\mathrm{s}$ is the region suffix $(s \in S, S=\{1, \ldots, R\}), i, j$ are industrial sector suffixes $(i, j \in N, N=\{1, \ldots$, $n), V_{j}^{s}$ is the amount of value added, $x_{i j}^{s}$ is the amount of composite goods for intermediate inputs, and $a_{v j}^{s}, a_{i j}^{s}$ are the input-output coefficients. From Equation 1, the uses of the composite goods and

\footnotetext{
7 Because the use of imports is not separated into intermediate and final demand in the original input-output table, one Armington composite for imported and domestic goods is used for both intermediate and final demand, as shown in the bottom terms. In total, the technology tree is consistent with the Japanese interregional I-O table that is used in this research.
} 
value added are obtained by

$$
\begin{aligned}
& x_{i j}^{s}=a_{i j}^{s} X d_{j}^{s}, \\
& V_{j}^{s}=a_{v j}^{s} X d_{j}^{s} .
\end{aligned}
$$

The requirements of capital and labor (the third term on the right-hand side in Figure 1) are determined by solving the cost-minimization problem

$$
\begin{gathered}
C_{v_{j}^{s}}\left(w_{j}^{s}, r_{j}^{s}\right) V_{j}^{s}=\min _{l_{j}, k_{j}^{s}} w_{j}^{s} l_{j}^{s}+r_{j}^{s} k_{j}^{s} \\
\text { s.t. } \quad f_{V_{j}^{s}}\left(l_{j}^{s}, k_{j}^{s}\right)=V_{j}^{s}
\end{gathered},
$$

where $w_{j}^{s}$ is wages, $\boldsymbol{r}_{j}^{s}$ is capital rent, $\boldsymbol{l}_{j}^{s}$ is labor input, $\boldsymbol{k}_{j}^{s}$ is capital input, and $C_{v_{j}^{s}}$ is the cost function for a single value added. As a value-added function $f_{V_{j}^{j}}$, the following Cobb-Douglas function (Equation 5) is assumed:

$$
f_{V_{j}^{s}}\left(l_{j}^{s}, k_{j}^{s}\right)=h_{j}^{s} l_{j}^{s a_{j}^{s}} k_{j}^{s 1-a_{j}^{s}},
$$

where $h_{j}^{s}$ is total factor productivity, and $a_{j}^{s}$ is output elasticity of labor $\left(1-a_{j}^{s}\right.$ : output elasticity of capital). Then, the following factor demands of labor and capital are obtained based on the costminimization problem (Equation 4).

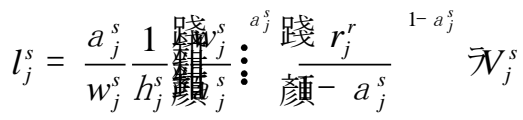

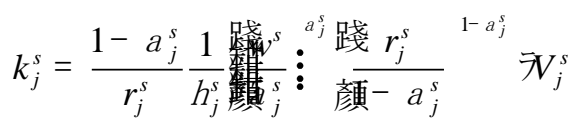

Next, composite goods on the left-hand side of the third term in Figure 1 are assumed to follow the CES production function with the input of goods (final products) from all regions. The Armington assumption is used for the composite procedure; therefore, each inbound imported good is treated as a different good. The use of the goods from each region is determined by the cost minimization problem given in Equation 8 as

$$
\begin{aligned}
& C_{x_{i j}^{s}} x_{i j}^{s}=\min _{x_{i j}^{r s}} \cdot \underset{r \text { 木s }}{ } P_{i}^{r} x_{i j}^{r s}
\end{aligned}
$$

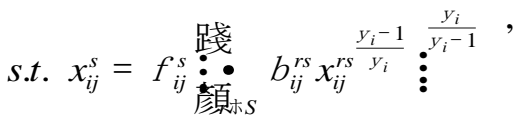

where $f_{i j}^{s}$ is a scale parameter, $b_{i j}^{r s}$ is a share parameter, and $y_{i}$ is an elasticity of substitution parameter. By solving Equation (8), the cost of composite good $C_{x_{i j}^{s}}$ is acquired.

$$
C_{x_{i j}^{s}}=\frac{1}{f_{i j}^{s}} \stackrel{\text { 鴿 }}{:_{r \text { 木 }}} b_{i j}^{r s y_{i}} P_{i}^{r 1-y_{i}} \frac{1}{1-y_{i}}
$$


Applying Shepard's lemma (derivative of equation (8)), the amount of inputs from each region $x_{i j}^{r s}$, for the interregional intermediate composite goods $x_{i j}^{s}$, is determined as follows:

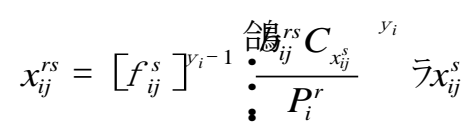

Then, the costs of domestic production $C_{X d_{j}^{s}}$ are determined via Equation 11.

$$
C_{X d_{j}^{s}} X d_{j}^{s}=C_{v_{j}^{s}} V_{j}^{s}\left(l_{j}^{s}, k_{j}^{s}\right)+\underset{i 木 I}{\bullet} C_{x_{i j}^{s}} x_{i j}^{s}
$$

Domestic products are combined with imported goods as shown in the first layer of Figure 1. Similar to Equation 8, the amounts of domestic and import goods are determined by the cost-minimization problem (Equation 11)

$$
\begin{aligned}
& P_{j}^{s} X_{j}^{s}=\min _{x d_{j}^{s}, x i m p_{j}^{s}}\left(P d_{j}^{s} x d_{j}^{s}+P m_{j}^{s} x i m p_{j}^{s}\right)
\end{aligned}
$$

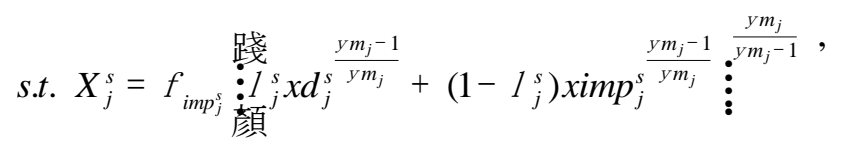

where $P_{j}^{s}$ is the price of composite goods, $P d_{j}^{s}$ and $P m_{j}^{s}$ are the prices of domestic and imported goods, respectively, $X_{j}^{s}$ is the total supply of composite goods, $f_{i m p_{j}}^{s}$ is a scale parameter, $I_{j}^{s}$ is a share parameter, and $y m_{j}$ is the elasticity of substitution.

Solving problem 12 yields:

$$
\left.P_{j}^{s}=\frac{1}{f_{i m p p_{j}^{s}}} \text { 鵨 }{ }_{j}^{s}\right)^{y m_{j}}\left[P d_{j}^{s}\right]^{1-y m_{j}}+\left(1-I_{i}^{s}\right)^{y m_{j}}\left[P m_{j}^{s}\right]^{1-y m_{j}} \frac{1}{1-y m_{j}} .
$$

Applying Shephard's lemma to Equation 13, inputs of domestic goods $x d_{j}^{s}$ and imports $x i m p_{i j}^{s}$ are specified as:

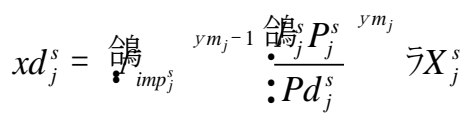

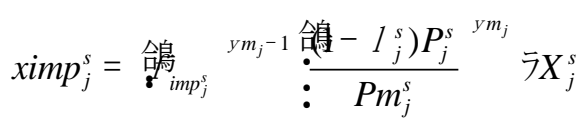

During a disaster, production capacity is reduced by the decrease in labor and capital factors, infrastructure disruption, or other adverse conditions. The restriction of the capital and labor markets by the disaster is reflected in the market conditions described later. The effects of infrastructure disruption on production capacity are explained by the change in total productivity factor $h_{j}^{s}$. The method for setting $h_{j}^{s}$ is given in the case study section. 
The domestic sales and exports are determined by the following profit-maximization problem based on the constant elasticity of technology (CET) function.

$$
\begin{aligned}
& \max _{x d_{j}^{s}, x e_{j}^{s}} p_{j}^{s} X d_{j}^{s}=P d_{j}^{s} x d_{j}^{1 s}+P e_{j}^{s} x e_{j}^{s}
\end{aligned}
$$

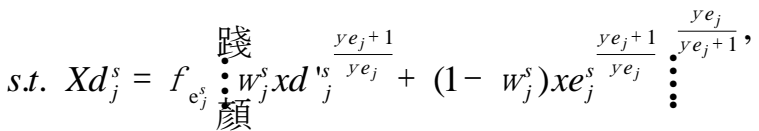

where $p_{j}^{s}$ is the price of domestic products, $P \boldsymbol{e}_{j}^{s}$ is the price of exports, $x \boldsymbol{e}_{j}^{s}$ is the supply of exports, $f_{\mathrm{e}_{j}^{s}}$ is a scale parameter, $x d_{j}^{\prime s}$ is a supply of domestic goods, $x e_{j}^{s} \quad$ is a supply of exports, $W_{j}^{s}$ is a share parameter, and $y \boldsymbol{e}_{j}$ is the elasticity of transformation. Solving problem (16) yields:

$$
\begin{aligned}
& \left.p_{j}^{s}=\frac{1}{f_{e_{j}^{s}}} \text { 鵨 }_{\mu_{j}^{s}}^{s}\right)^{-y e_{j}}\left[P d_{j}^{s}\right]^{1+y e_{j}}+\left(1-W_{j}^{s}\right)^{-y e_{j}}\left[P e_{j}^{s}\right]^{1+y e_{j}} \frac{1}{1+y e_{j}},
\end{aligned}
$$

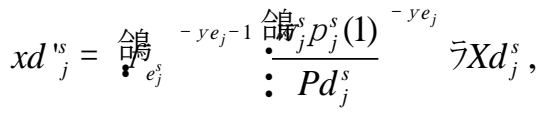

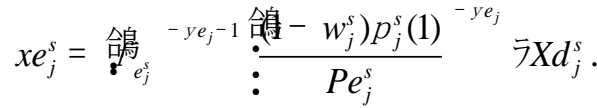

Figure 1. Technology Tree 


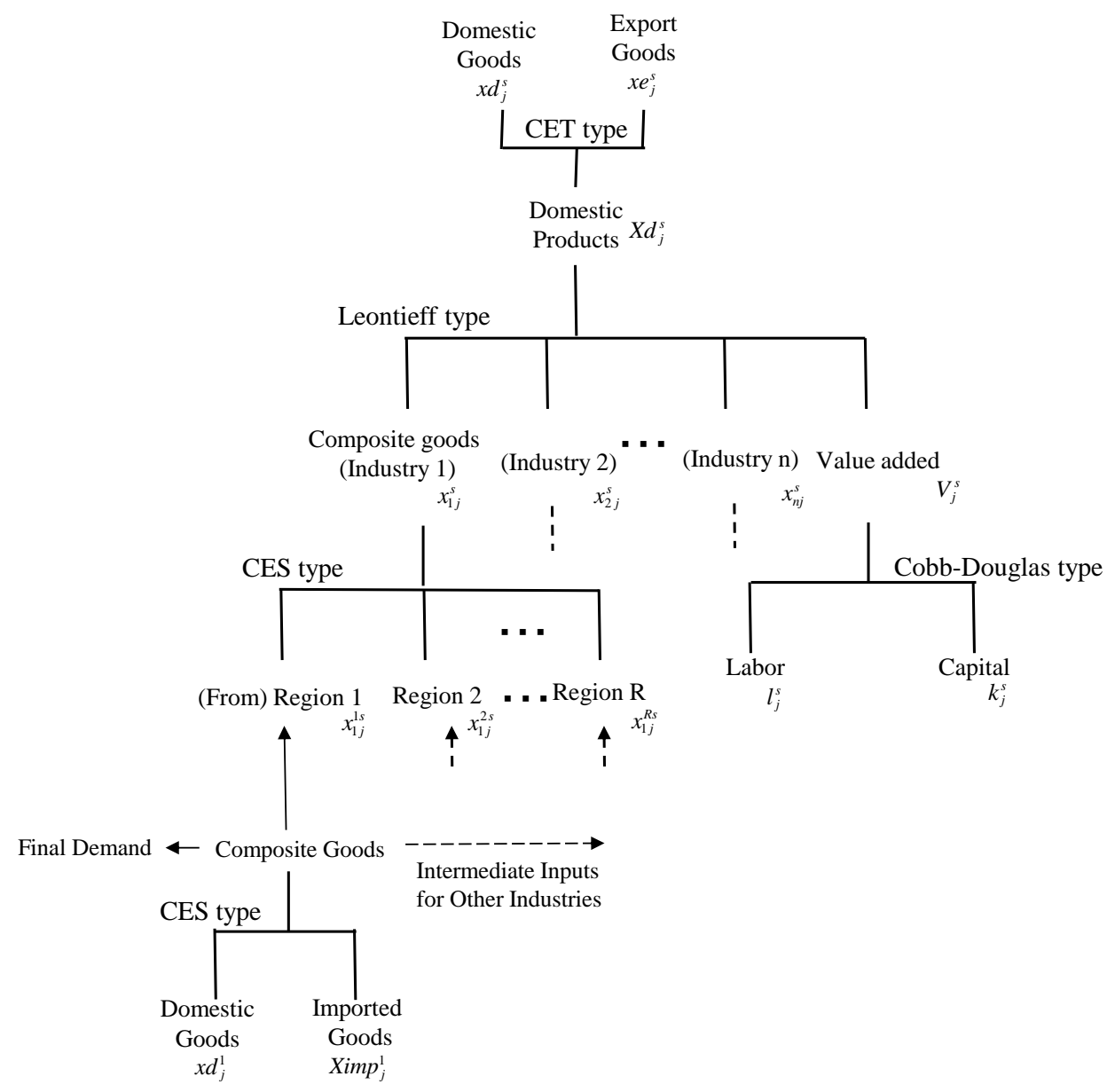

2) Household sector

Households determine the consumption of goods by the utility-maximization problem

$$
\begin{aligned}
& V^{s}=\max U^{s}\left(F_{1}^{s}, \mathrm{~L}, F_{N}^{s}\right) \\
& \text { s.t. } \underset{j \neq N}{ } P_{F_{j}^{f}} F_{j}^{s}=I^{s}
\end{aligned}
$$

where

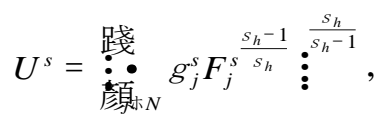

and $V^{s}$ is an indirect utility function, $U^{s}$ is a direct utility function, $F_{j}^{s}$ is demand for goods, $P_{F_{j}^{s}}$ is the consumer price of goods, $g_{j}^{s}$ is a share parameter of goods, $S_{h}$ is an elasticity of substitution parameter, and $I^{s}$ is an income.

Solving problem (20), $F_{j}^{s}$ is obtained as follows:

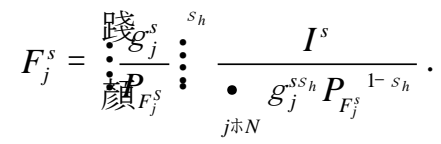

Similarly, the cost minimization behavior of households with respect to the consumption of regional 
goods is provided in the form of Equation 23.

$$
\begin{aligned}
& P_{F_{j}^{s}} F_{j}^{s}=\min _{d_{j}^{r s}} \underset{r \text { 米 } S}{ } P_{j}^{r} d_{j}^{r s} \\
& \text { s.t. } F_{j}^{s}=t_{j}^{s} \text { 踐 }
\end{aligned}
$$

Here, $t_{j}^{s}$ is a scale parameter, $g_{j}^{r s}$ is a share parameter, $s_{f_{j}}$ is an elasticity of substitution parameter, and $d_{j}^{r s}$ is the interregional import of goods $j$. From Equation 23, the price of goods is determined as:

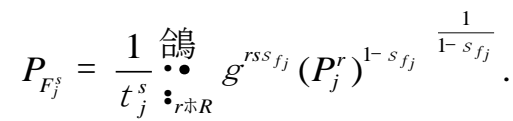

From Shepard's lemma, demand for composite goods delivered from each region is determined by

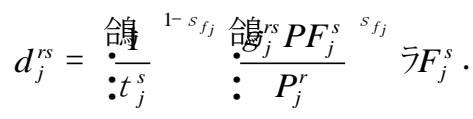

Income in the normal period (i.e., not a disaster period) is determined by labor supply $l_{j}^{s(0)}$, capital stock $k_{j}^{s(0)}$, wage $w_{j}^{(0)}$, capital rent $r^{s(0)}$, and regional transfers of income $N X^{s(0) 8}$ using the equation

$$
I^{s(0)}=\underset{j 末 N}{\bullet}\left(w_{j}^{(0)} l_{j}^{s(0)}+r^{s(0)} k_{j}^{s(0)}\right)-N X^{s(0)} .
$$

During a disaster, nominal income is assumed to be the same as in the normal period.

$$
I^{s(1)}=I^{s(0)}
$$

Equation 26-1 assumes no change occurs between the normal and disaster periods. That is, the difference in the ability to buy goods among regions is unchanged for two periods. The regional transfer of income $N X^{s(0)}$ is presumed to be identical for simplicity.

\section{3) Market Equilibrium Conditions}

Market equilibrium conditions are given for conditions (a) and (b). In particular, the factor market equilibrium condition is used to explain the downward factor price rigidity and unemployment (including temporary reduction of labor) during disasters.

(a) Goods market clearing condition

The goods market clearing condition is represented by

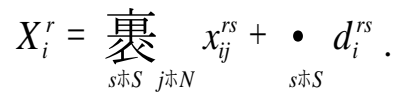

(b) Factor market equilibrium condition

The factor market equilibrium condition for each daily period, which allows the movement of

\footnotetext{
${ }^{8}$ The redistribution of income among regions can occur through policies, such as tax and social security spending. 
capital among sectors and the movement of labor among regions, is given as

$$
\begin{aligned}
& \underset{\text { 裹 }}{\text { 戠 }} l_{j}^{s(0)}=\underset{s \text { 水 }}{ } L_{j}^{s(0)}
\end{aligned}
$$

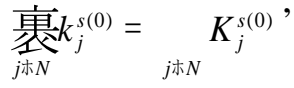

where $L_{j}^{s(0)}$ and $K_{j}^{s(0)}$ are intimal endowments. Factor market conditions during a disaster can be set by the downward price rigidity assumption of labor. In that case, the following conditions can be considered valid:

$$
\begin{aligned}
\left(w_{j}^{s(1)}-w_{j}^{s(0)}\right)\left(l_{j}^{s(1)}-L_{j}^{s(1)}\right) & \left.=0, \text { where } w_{j}^{s(1)} \text { ウ } w_{j}^{s(0)}, l_{j}^{s(1)}\right\rfloor L_{j}^{s(1)} . \\
k_{j}^{s(1)}-K_{j}^{s(1)} & =0
\end{aligned}
$$

Here, $L_{j}^{s(1)}=\left(1-X_{l_{j}}\right) L_{j}^{s(0)}, K_{j}^{s(1)}=\left(1-X_{k_{j}^{j}}\right) K_{j}^{s(0)}$, and $X_{l_{j}^{5}}, X_{k_{j}^{j}}$ are the damage ratios of labor and capital, respectively. The prices of capital $r_{j}^{s(1)}$ and labor $w_{j}^{s(1)}$ take distinct values among regions and sectors.

\section{Application to the Case of the 2011 Great East Japan Earthquake and Tsunami}

\subsection{Case Study Settings}

In this section, we describe the datasets used in the model for the case of the 2011 Great East Japan Earthquake. The major datasets include the interregional input-output table for Japan, a set of elasticity of substitution parameters, and PCLR.

Figure 2 illustrates the input-output table published by the Ministry of Economy, Trade and Industry in 2005 (METI, 2010) for the nine regions in Japan. The production shocks occurred in Tohoku and part of the Kanto region. Table 1 shows its 30 industrial sectors and highlights Electronics and Automobile parts, which are a focus of our analysis. In fact, the production decrease in the overall transportation manufacturing sector is attributable to the damages to the small parts products in these sectors.

The elasticity of substitution parameters for interregional composite goods (interregional trade) are critical for evaluating the cascading effects caused by supply-chain damage. In Japan, these values for manufacturing sectors are estimated by Koike et al. (2012), as described previously. The values range from $0.74-0.96$, which are considered relatively small for a normal period considering that Rose and Guha (2004) indicate the input elasticities are generally less than 1 in the short-run case (less than six months after a disaster).

Because it is unlikely that the substitutability is higher in manufacturing sectors than in nonmanufacturing sectors, the elasticity of substitution for the nonmanufacturing sector is somewhat arbitrarily set to 0.25 . In addition, we simulate an elasticity of 0 in either or both of the automobile parts and electronics sectors; this supposes that supply-chain effects are particularly important in these sectors.

The elasticity between different composite goods for final demand is set at 0.8 based on Ichioka (1991). Concerning the substitution or transformation parameters between domestic and imported goods or export goods, the present work uses smaller values (manufacturing: 0.50; nonmanufacturing: 0.25), indicating that substitution of imports during a disaster is also small (the price of imported goods remains the same before and after the disasters). The baseline elasticity of substitution parameters (Base Case) is summarized in Table 2. 
Figure 2. Classification of regions

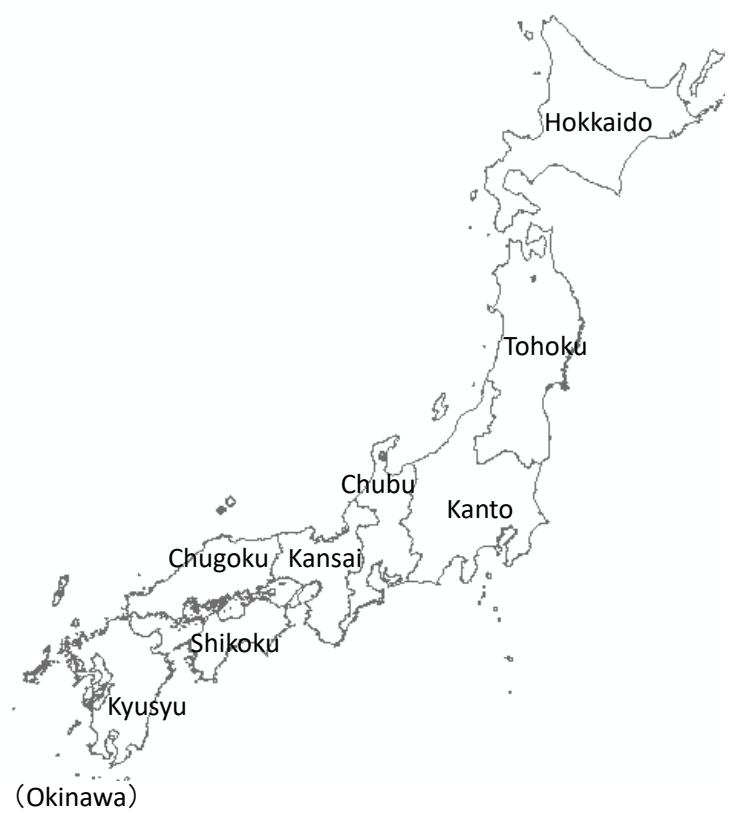

Table 1. Classification of industrial sectors

Agriculture, forestry, and fishery

Mining

Food

Apparel and textile

Wood and wood products

Paper/pulp

Chemicals

Refineries and coal

Glass/stone/clay

Steel

Non-ferrous metal

Metal

General machinery

Electrical machinery

Electronics
Transportation machinery

(Passenger cars)

Transportation machinery

(Other finished products)

Transportation machinery

(Automobile parts)

Precision machinery

Other manufacturing

Construction

Utilities

Communication

Transportation

Wholesale and retail

Financial, insurance, and real estate

Medical services

Business services

Personal services

Others

Table 2. Parameter values for the elasticity of substitution in Japan

\begin{tabular}{|c|c|c|}
\hline Classification & Sector & Values \\
\hline $\begin{array}{c}\text { Interregional } \\
\text { composite goods }\end{array}$ & Manufacturing & $\begin{array}{c}0.74-0.96 \\
\text { (Koike et al., 2012) }\end{array}$ \\
\hline
\end{tabular}




\begin{tabular}{|c|c|c|} 
& Nonmanufacturing & 0.25 \\
\hline $\begin{array}{c}\text { Demand for final } \\
\text { composite goods }\end{array}$ & All sectors & 0.8 \\
\hline $\begin{array}{c}\text { Imported and } \\
\text { domestic final } \\
\text { goods }\end{array}$ & Manufacturing & 0.5 \\
\cline { 2 - 3 } & Nonmanufacturing & 0.25 \\
\hline
\end{tabular}

As a basic scenario for the disaster shock in the models, we adopt the PCLRs estimated by Kajitani and Tatano (2014). The primary causes that increase PCLRs are assumed damage to production facilities, labor supply, and infrastructure. While reductions in labor affect production capacity, at least in the case of past earthquakes in Japan, damage to the production facility is the dominant factor.

The conversion of the PCLRs to the shocks of value-added function in a CGE model is explained as follows. First, recall Equation 5 for the disaster case

$$
f_{V_{j}^{s}}\left(L_{j}^{s(1)}, K_{j}^{s(1)}\right)=h_{j}^{s(1)}\left(L_{j}^{s(1) a_{j}^{s}} K_{j}^{s(1)^{1-a_{j}^{s}}}\right) .
$$

Then, the PCLR and production functions have the following relationship:

$$
1-P C L R_{j}^{s}=h_{j}^{s(1)}\left(L_{j}^{s(1) a_{j}^{s}} K_{j}^{s(1)^{1-a_{j}^{s}}}\right) / h_{j}^{s(0)}\left(L_{j}^{s(0) a_{j}^{s}} K_{j}^{s(0) 1^{1-a_{j}^{s}}}\right) .
$$

Here, we assume that the infrastructure disruption affects only parameter $h_{j}^{s(1)}$. Setting $\overline{P C L R}_{j}^{s}$ as the estimate under an assumption that key infrastructure was not disrupted, which is also available in Kajitani and Tatano (2014), the relationships in equation (30) can be rewritten as:

$$
1-\overline{P C L R}_{j}^{s}=\left(L_{j}^{s(1) a_{j}^{s}} K_{j}^{s(1)^{1-} a_{j}^{s}}\right) /\left(L_{j}^{s(0) a_{j}^{s}} K_{j}^{s(0) 1^{-} a_{j}^{s}}\right),
$$

because $h_{j}^{s(1)}$ is identical to $h_{j}^{s(0)}$.

From Equations 30 and 31, $h_{j}^{s(1)}$ can be estimated as

$$
h_{j}^{s(1)}=\frac{\left(1-P C L R_{j}^{s}\right) h_{j}^{s(0)}}{1-\overline{P C L R}_{j}^{s}} .
$$

Considering that the input structure for capital and labor follows a putty-clay assumption in the area affected by a disaster, the production restriction is determined by either factor, and the following relationship holds:

$$
\frac{K_{j}^{s(1)}}{K_{j}^{s(0)}}=\frac{L_{j}^{s(1)}}{L_{j}^{s(0)}}=1-\overline{P C L R}_{j}^{s} .
$$

By using Equations 32 and 33, PCLR is converted to the shock to the value-added function in a CGE model. Note that $K_{j}^{s(1)}$ and $L_{j}^{s(1)}$ are interpreted as hypothetical capital and labor endowments,

\footnotetext{
9 The alternative approach could be that PCLR is reflected in only the hypothetical capital and labor losses. However, we reflect the impacts of infrastructure disruptions on the efficiency parameter because the interpretation is easier on the capital and labor losses.
} 
respectively, because the corresponding PCLRs consider the functional damage to production facilities, which is different from so-called stock losses (in monetary terms) and employee losses.

The PCLRs for the Great East Japan Earthquake are estimated for Iwate, Miyagi, and Fukushima prefectures (Tohoku region) and for the Ibaraki and Tochigi prefectures (Kanto region) in the previous study (Kajitani and Tatano, 2014). Because production capacities in the other prefectures in the Tohoku region (Akita, Aomori, and Yamagata) are not considered, the index of industrial production is used for manufacturing sectors, and no shock is considered for non-manufacturing sectors in these prefectures. To obtain the overall production capacities in the Tohoku and Kanto regions, the average production capacities weighted by the number of employees in each prefecture are used. This basic shock scenario in the model is used in this study.

\subsection{Case Study Results}

\section{(1) Effects of the Substitution Parameter Values}

To compare the performance of the models using different substitution parameter values, root mean square errors (RMSEs) are used, as calculated from the estimated and observed IIPs. ${ }^{10}$ Sensitivity analysis of the elasticity of the substitution parameters for composite goods among domestic regions is performed with parameter values that are $1 / 4,1 / 3$, and $1 / 2$ of, and equal to, the value of the base case for all of the sectors. In addition, the 0 (Leontief) case is applied to the substitution parameters in the Automobile parts and Electronics sectors. For the substitution parameters between domestic and imported goods or export goods, the 0 (Leontief) case is employed, except in the base case.

Table 3 lists the results for the different combinations of substitution parameter values for both intermediate inputs and final demand for March, April, and May 2011. The results for each month are provided in the Appendix 2 (supplemental data). In all cases, the basic parameters except exogenous substitution parameters are calibrated such that all of the endogenous variables, including production, have very small residuals compared with the benchmark datasets.

The result of the base case (No. 1) has the largest RMSEs among all of the estimates. Thus, the baseline parameter values are not suitable for short-run disaster impact assessment. In all of the calculations (see the tables in the Appendix 2), 0 is supported for use as the substitution or transformation parameters between domestic and international goods. Thus, the comparisons are made among the 0 cases.

Overall, No. 20 ( 0 for automobile parts; $1 / 3$ for other sectors both in intermediate and final demand) produces the estimate with the least RMSE (0.1126). Both No. 14 and No. 17 are competitive estimates (RMSE=0.1127), but the Wilcoxon signed-rank test (Wilcoxon, 1945) detects the difference between the mean ranks of two (paired) samples at a significance level of $1 \%$. The difference between RMSEs appears slight, but No. 20 more consistently produces smaller errors in many estimated IIPs in comparison with No. 14 and No. 17. The absolute values of substitution parameters are given in Table 4.

Because the estimates from the models with the substitution parameter of Automobile parts set to 0 generally fit better with the observed IIPs, the substitution parameter of Automobile parts likely must be set to a very small value, both immediately following the disaster as well as for several months thereafter. But the 0 -elasticity case is not supported for the Electronics sector ${ }^{11}$.

\footnotetext{
10 For a comparison, automobile parts, passenger cars, and other finished transportation machinery products are aggregated by the weights of value added.

11 In fact, the large supply-chain impacts for Transportation machinery resulted from damage to a semiconductor company, which is classified as Electronics. This type of supply-chain impact must be analyzed using a different framework, such as using a micro business transaction dataset.
} 
The smallest RMSEs by region are obtained from different models. The most rigid model, No. 37 (Automobile parts: 0; Electronics: 0; other sectors: 1/4 for both intermediate and final demand), succeeds in representing the damage that occurred in the Kanto region, but the extent of damage might be overestimated both in the Tohoku and remaining regions. In contrast, No. 17 (Automobile parts: 0; Electronics: 0; other sectors: $1 / 2$ for both intermediate and final demand) produces the best estimates for both Tohoku and other regions, excluding Kanto, but might underestimate the effects in the Kanto region. Therefore, No. 20 ( 0 for Automobile parts; 1/3 for other sectors both in intermediate and final demand) is supported as a compromise case between No. 17 and No. 37.

Table 3. Root mean square errors of the estimated IIPs in March, April, and May

\begin{tabular}{|c|c|c|c|c|c|c|c|c|c|c|c|}
\hline & & \multicolumn{3}{|c|}{ Intermediate $(y)$} & \multicolumn{3}{|c|}{ Final Demand $\left(\sigma_{f}\right)$} & \multicolumn{4}{|c|}{ Root Mean Square Errors } \\
\hline No. & $\begin{array}{c}\text { Exp } \\
\& \\
\text { Imp }\end{array}$ & $\begin{array}{l}\text { Auto } \\
\text { Parts }\end{array}$ & Elec. & Other & $\begin{array}{l}\text { Auto } \\
\text { Parts }\end{array}$ & Elec. & Other & All & Tohoku & Kanto & Other \\
\hline 1 & $1 / 2$ & 1 & 1 & 1 & 1 & 1 & 1 & 0.1329 & 0.1664 & 0.1465 & 0.1235 \\
\hline 2 & 0 & 1 & 1 & 1 & 1 & 1 & 1 & 0.1318 & 0.1632 & 0.1441 & 0.1231 \\
\hline 3 & 0 & $1 / 2$ & $1 / 2$ & $1 / 2$ & 1 & 1 & 1 & 0.1309 & 0.1621 & 0.1405 & 0.1228 \\
\hline 4 & 0 & $1 / 2$ & $1 / 2$ & $1 / 2$ & $1 / 2$ & $1 / 2$ & $1 / 2$ & 0.1298 & 0.1628 & 0.1368 & 0.1218 \\
\hline 5 & 0 & $1 / 3$ & $1 / 3$ & $1 / 3$ & 1 & 1 & 1 & 0.1296 & 0.1619 & 0.1342 & 0.1223 \\
\hline 6 & 0 & $1 / 3$ & $1 / 3$ & $1 / 3$ & $1 / 2$ & $1 / 2$ & $1 / 2$ & 0.1290 & 0.1628 & 0.1328 & 0.1215 \\
\hline 7 & 0 & $1 / 3$ & $1 / 3$ & $1 / 3$ & $1 / 3$ & $1 / 3$ & $1 / 3$ & 0.1287 & 0.1634 & 0.1315 & 0.1211 \\
\hline 8 & 0 & $1 / 4$ & $1 / 4$ & $1 / 4$ & 1 & 1 & 1 & 0.1293 & 0.1663 & 0.1265 & 0.1222 \\
\hline 9 & 0 & $1 / 4$ & $1 / 4$ & $1 / 4$ & $1 / 2$ & $1 / 2$ & $1 / 2$ & 0.1289 & 0.1655 & 0.1252 & 0.1221 \\
\hline 10 & 0 & $1 / 4$ & $1 / 4$ & $1 / 4$ & $1 / 3$ & $1 / 3$ & $1 / 3$ & 0.1287 & 0.1653 & 0.1241 & 0.1221 \\
\hline 11 & 0 & $1 / 4$ & $1 / 4$ & $1 / 4$ & $1 / 4$ & $1 / 4$ & $1 / 4$ & 0.1286 & 0.1653 & 0.1235 & 0.1220 \\
\hline 12 & 0 & 0 & 1 & 1 & 1 & 1 & 1 & 0.1165 & 0.1591 & 0.1083 & 0.1089 \\
\hline 13 & 0 & 0 & $1 / 2$ & $1 / 2$ & 1 & 1 & 1 & 0.1160 & 0.1581 & 0.1057 & 0.1089 \\
\hline 14 & 0 & 0 & $1 / 2$ & $1 / 2$ & $1 / 2$ & $1 / 2$ & $1 / 2$ & 0.1127 & 0.1596 & 0.1015 & 0.1045 \\
\hline 15 & 0 & 0 & 1 & 1 & 0 & 1 & 1 & 0.1162 & 0.1596 & 0.1084 & 0.1083 \\
\hline 16 & 0 & 0 & $1 / 2$ & $1 / 2$ & 0 & 1 & 1 & 0.1159 & 0.1581 & 0.1055 & 0.1087 \\
\hline 17 & 0 & 0 & $1 / 2$ & $1 / 2$ & 0 & $1 / 2$ & $1 / 2$ & 0.1127 & 0.1596 & 0.1014 & 0.1044 \\
\hline 18 & 0 & 0 & $1 / 3$ & $1 / 3$ & 0 & 1 & 1 & 0.1160 & 0.1582 & 0.1006 & 0.1097 \\
\hline 19 & 0 & 0 & $1 / 3$ & $1 / 3$ & 0 & $1 / 2$ & $1 / 2$ & 0.1134 & 0.1597 & 0.0971 & 0.1061 \\
\hline 20 & $\mathbf{0}$ & $\mathbf{0}$ & $1 / 3$ & $1 / 3$ & 0 & $1 / 3$ & $1 / 3$ & 0.1126 & 0.1606 & 0.0943 & 0.1052 \\
\hline 21 & 0 & 0 & $1 / 4$ & $1 / 4$ & 0 & 1 & 1 & 0.1177 & 0.1625 & 0.0952 & 0.1118 \\
\hline 22 & 0 & 0 & $1 / 4$ & $1 / 4$ & 0 & $1 / 2$ & $1 / 2$ & 0.1155 & 0.1623 & 0.0911 & 0.1094 \\
\hline 23 & 0 & 0 & $1 / 4$ & $1 / 4$ & 0 & $1 / 3$ & $1 / 3$ & 0.1152 & 0.1626 & 0.0890 & 0.1091 \\
\hline 24 & 0 & 0 & $1 / 4$ & $1 / 4$ & 0 & $1 / 4$ & $1 / 4$ & 0.1152 & 0.1629 & 0.0879 & 0.1092 \\
\hline 25 & 0 & 0 & 0 & 1 & 1 & 1 & 1 & 0.1161 & 0.1628 & 0.1025 & 0.1083 \\
\hline 26 & 0 & 0 & 0 & $1 / 2$ & 1 & 1 & 1 & 0.1158 & 0.1617 & 0.1002 & 0.1085 \\
\hline 27 & 0 & 0 & 0 & $1 / 2$ & $1 / 2$ & $1 / 2$ & $1 / 2$ & 0.1138 & 0.1617 & 0.0951 & 0.1065 \\
\hline 28 & 0 & 0 & 0 & 1 & 0 & 0 & 1 & 0.1160 & 0.1638 & 0.1017 & 0.1080 \\
\hline 29 & 0 & 0 & 0 & $1 / 2$ & 0 & 0 & 1 & 0.1157 & 0.1626 & 0.0994 & 0.1083 \\
\hline 30 & 0 & 0 & 0 & $1 / 2$ & 0 & 0 & $1 / 2$ & 0.1129 & 0.1620 & 0.0937 & 0.1053 \\
\hline
\end{tabular}




\begin{tabular}{llllllllllll}
31 & 0 & 0 & 0 & $1 / 3$ & 0 & 0 & 1 & 0.1161 & 0.1624 & 0.0962 & 0.1095 \\
32 & 0 & 0 & 0 & $1 / 3$ & 0 & 0 & $1 / 2$ & 0.1137 & 0.1619 & 0.0905 & 0.1070 \\
33 & 0 & 0 & 0 & $1 / 3$ & 0 & 0 & $1 / 3$ & 0.1136 & 0.1621 & 0.0877 & 0.1071 \\
34 & 0 & 0 & 0 & $1 / 4$ & 0 & 0 & 1 & 0.1179 & 0.1650 & 0.0924 & 0.1118 \\
35 & 0 & 0 & 0 & $1 / 4$ & 0 & 0 & $1 / 2$ & 0.1162 & 0.1641 & 0.0870 & 0.1104 \\
36 & 0 & 0 & 0 & $1 / 4$ & 0 & 0 & $1 / 3$ & 0.1162 & 0.1640 & 0.0845 & 0.1108 \\
37 & 0 & 0 & 0 & $1 / 4$ & 0 & 0 & $1 / 4$ & 0.1165 & 0.1640 & $\mathbf{0 . 0 8 3 4}$ & 0.1113 \\
\hline
\end{tabular}

Table 4. Absolute values of CES parameters for the best estimate case

\begin{tabular}{ccc} 
Sector Name & $y$ & $s_{f}$ \\
\hline Agriculture, forestry, and fishery & 0.277 & 0.277 \\
Mining & 0.267 & 0.267 \\
Food & 0.283 & 0.283 \\
Apparel and textile & 0.290 & 0.290 \\
Wood and wood products & 0.290 & 0.290 \\
Paper/pulp & 0.283 & 0.283 \\
Chemicals & 0.260 & 0.260 \\
Refineries and coal & 0.293 & 0.293 \\
Glass/stone/clay & 0.300 & 0.300 \\
Steel & 0.270 & 0.270 \\
Non-ferrous metal & 0.247 & 0.247 \\
Metal & 0.280 & 0.280 \\
General machinery & 0.287 & 0.287 \\
Electrical machinery & 0.297 & 0.297 \\
Electronics & 0.297 & 0.297 \\
Transportation machinery & 0.320 & 0.320 \\
(Passenger cars) & & \\
Transportation machinery & 0.320 & 0.320 \\
(Other finished products) & & \\
Transportation machinery & 0.000 & 0.000 \\
(Automobile parts) & 0.310 & 0.310 \\
Precision machinery & 0.290 & 0.290 \\
Other manufacturing & 0.083 & 0.083 \\
Other non-manufacturing & &
\end{tabular}

\section{(2) Characteristics of the Results Derived from the Best Model}

Next, we discuss the characteristics of the best model (No. 20). Figure 3 compares the estimated production level for all manufacturing sectors and the corresponding IIP in each region for each month. ${ }^{12}$ The overall trend in the estimated IIPs is consistent with the observed IIPs in the damaged areas (Tohoku and Kanto) and in the non-damaged areas. The estimates of the base case model (No. 1

\footnotetext{
${ }^{12}$ All effects are negative because of the assumption that factor endowments are fully utilized (maximum production is achieved) and unchangeable among regions and sectors. However, in actuality, some of the sectors in non-damaged regions benefit from a disaster. This phenomenon can be understood by considering an idle capacity before a disaster, but the degree of idle capacity must be explored in further research. 
in Table 3) are also plotted in the figure, but doing so does not decrease the IIPs as much as was observed. The supply-chain effects are not expressed by the model with the baseline parameter values.

Even in the estimates obtained from the best model, particularly in the Chubu region, the model consistently overestimates the production in each month. The supply-chain effects might not be adequately reflected in the model in the primary industrial sectors, such as the transportation machinery sector in the Chubu region. In Figure 4, the observed and estimated IIPs in the Transportation machinery sector are compared. In some of the regions, including the Chubu region, production values are overestimated by the model, which only accounted for the size of the supply shock given to the Transportation machinery sector itself in the Tohoku region. In actuality, the production decrease was significant in the Kanto region due to the damage to the semiconductor company, which decreased the production in Chubu and other regions at a larger scale than was estimated.

Figure 5 shows the contributions of the different causes of the decreased production by sector in Tohoku, Kanto, Chubu, and other regions. The decrease in production level is shown using a threemonth average (sum of decreased IIP values divided by three). The major causes primarily include factor damage, lifeline damage, and the general equilibrium effect. Factor and utility damage are exogenously set as a shock in Tohoku and Kanto, and general equilibrium effects are incremental effects calibrated by the CGE model.

Large general equilibrium effects occur in the nondamaged regions in particular. For example, many sectors in the Chubu region are affected by the effects of the disaster in the Tohoku and Kanto regions because the volumes of interregional trade between these regions are large during normal periods. The decrease in production level was largest in the transportation machinery sector; the steel and nonferrous metal sectors also showed large reductions in production levels because of the interindustry relationships with the transportation machinery sector.

Overall, general equilibrium effects are smaller in many sectors in the Tohoku region due to limitations in the model's focus on these sectors and regions. Within the same sector in the same region, the types of goods and services are assumed to be identical. In addition, businesses are viewed as being ideally matched, and inter-industry relationships are constructed with no time delays or costs, even during the disaster. In reality, such assumptions might not hold in many cases. These cases exist because of current limitations in the application of the CGE model to disasters, although the model could be extended by improving its focus on individual sectors and regions.

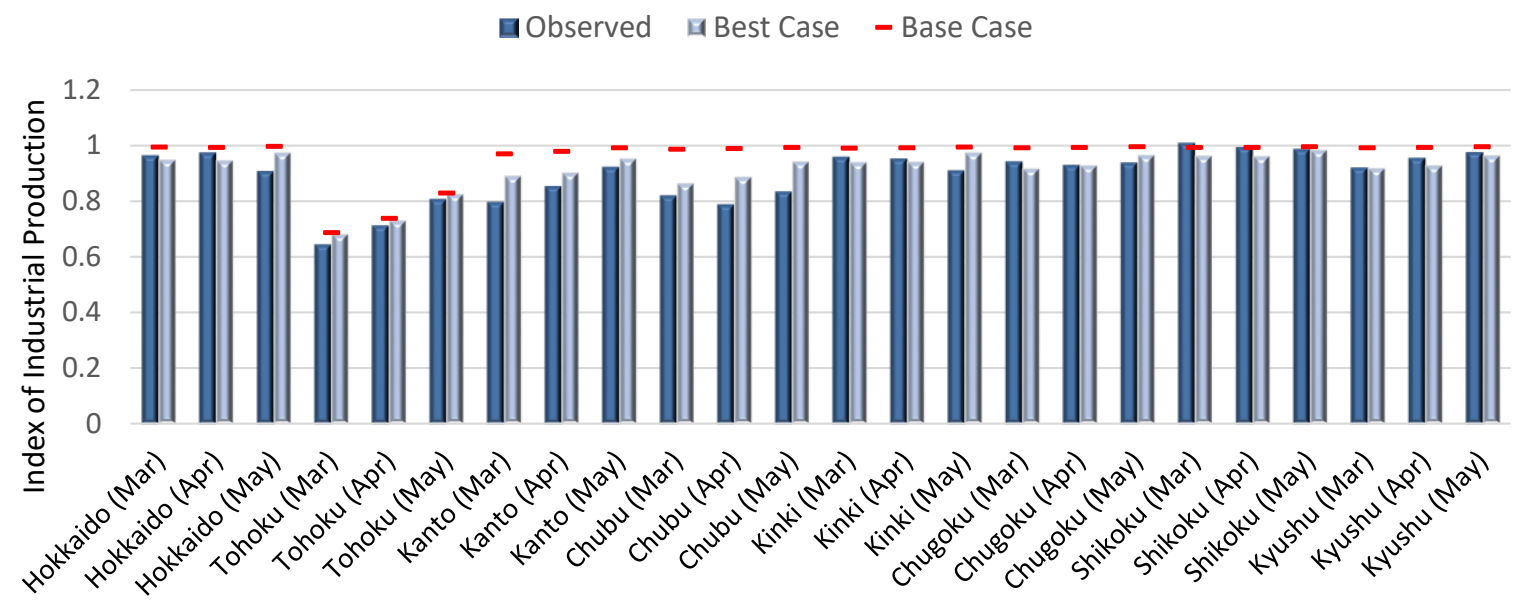


Figure 3. Comparison of IIP in each region and the corresponding estimates for the base and best-case scenarios

日Observed 回Best Case - Base Case

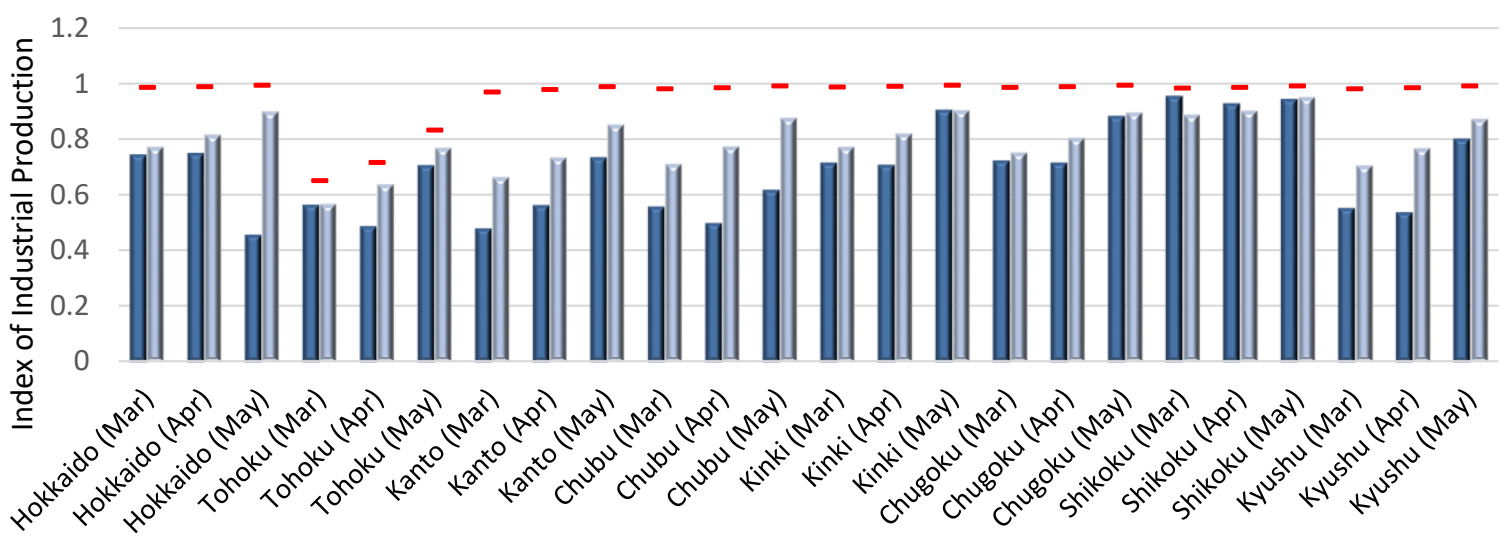

Figure 4. Comparison of IIP of the transportation machinery sector in each region and the corresponding estimates for the base and best-case scenarios 


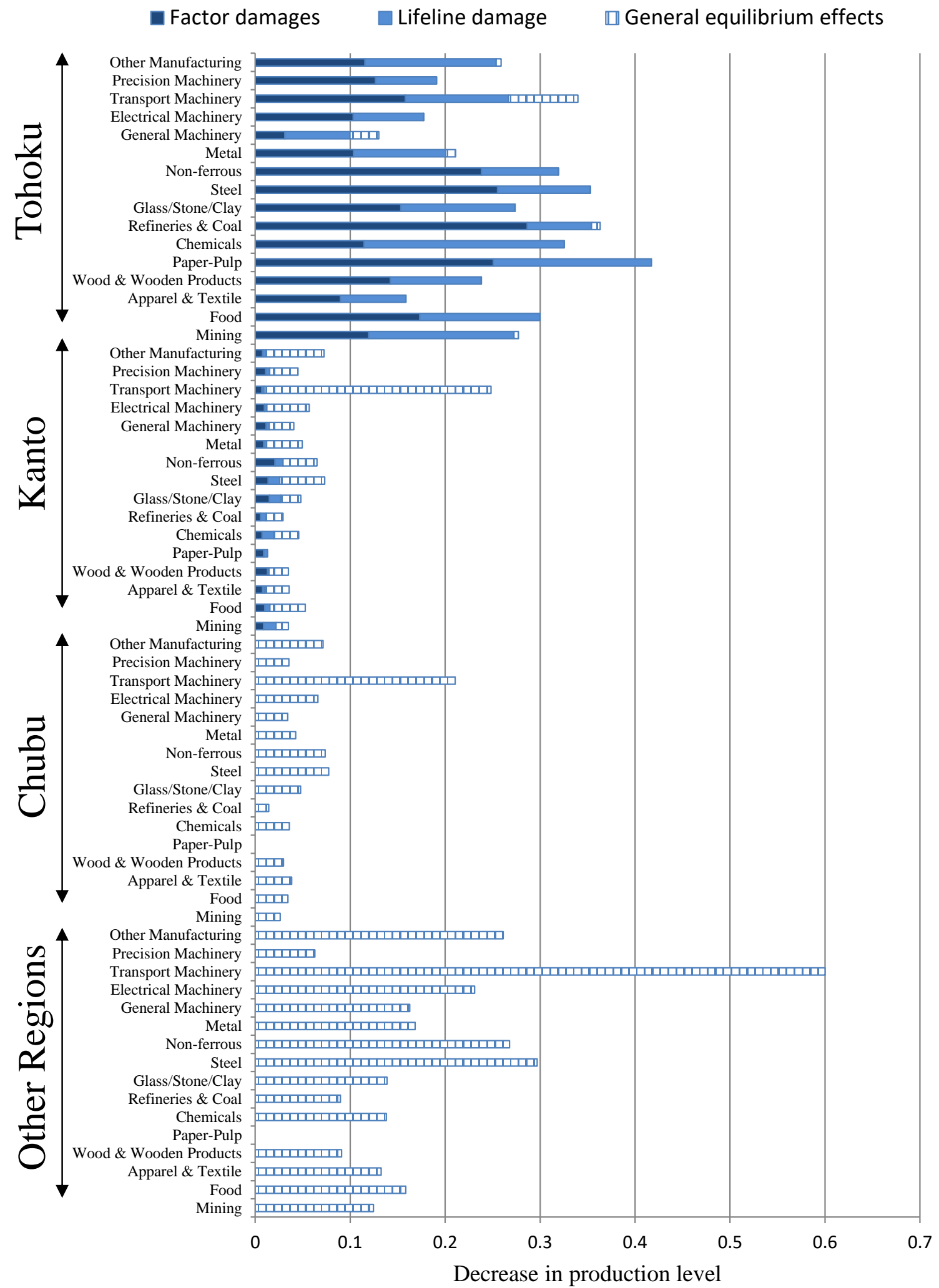

Figure 5. Ratio of production decrease in each region classified by damage source 


\subsection{Discussion}

The case study on the application of CGE models to the 2011 Great East Japan Earthquake and Tsunami demonstrates promising results, indicating that plausible settings can make CGE models suitable for disaster impact analysis, at least for short-run cases (several months after a disaster). These settings include nonmobile capital and labor and no income change, which are typical assumptions in a shortrun simulation of a CGE model. In particular, the substitution parameters are key for properly representing supply-chain damage in a disaster.

Our case study supports setting the substitution parameter to 0 for interregional trade in the automobile parts sector and to $1 / 3$ in other sectors, which produces countrywide supply-chain disruption in a disaster. These settings can be a reference in impact analyses of future disasters. Because these settings can depend upon specific contexts in the economy and disasters of Japan, it is necessary to carefully investigate the settings through additional case studies. The successful application of the model with the same settings to other disasters would be a true validation of the model because our model derived only fitted values for a specific case.

The smaller possibility of substitution, which is supported by our case study, indicates that the IO models, particularly those built to explain both supply- and demand-side effects, can be a viable alternative. To determine which model should be chosen, a comparative study between the CGE and IO models is necessary in terms of forecasting capabilities in real disasters and the effort (costs) to construct models.

Conversely, in the base case (ordinary substitution parameter values), hardly any supply-chain damages are observed (see Figure 3). This means that the base case results underestimate both the damages and benefits of countermeasures. So fine-tuning parameter values is important for proper disaster risk and countermeasure evaluations.

In essence, the substitution parameter value in each sector indicates resilience, reflecting how many countermeasures are installed concerning the substitution of goods and services in different places. The transportation sector in Japan, which experienced the Great East Japan Earthquake, has increased the substitutability of automobile parts and achieved faster recovery in the case of the 2016 Kumamoto Earthquake (Nishinihon Shinbun, 2016). Therefore, the estimated value of its elasticity of substitution could indicate that industry's economic resilience.

The use of PCLR instead of stock losses should increase the accuracy of estimating flow losses. In particular, in short-run settings, the production capacity losses, which can be thought of as functional damage to production systems, are the primary source of production shocks. Building damage and lifeline disruption, and even minor dislocation of machinery, can affect production capacity. These losses cannot be measured by stock losses. But, in such a treatment, costs of capital recovery are not directly linked to production capacity. So this type of setting might be valid only in the short-run, but the linkage between recovery cost and capital must be considered for the analysis of longer periods. In addition, our model is only specific to cases in which supply shocks dominate the demand-side effects. Model validation should be extended to consider behavioral changes and recovery investments. In any cases, because the PCLRs are estimated from an engineering model with an input of hazard information, both engineering and economic models should continue to be refined with respect to their ability to forecast the economic effects of natural disasters.

As we explained in the course of the literature review, model validation at a monthly frequency is challenging. The results of this case study are a reference case and demonstrate the potential applicability of a CGE model to this time scale; but the possibility exists that researchers can enhance the forecasting capability of a CGE model by extending the production system from static to dynamic 
by incorporating adaptation behavior in each industry. For promoting this dimension, it is useful to review such extensions of a model both in CGE and IO framework. As employed in Okuyama et al. (2007), SIM is one way to extend a CGE model to describe the time-phased production system after a disaster. In any cases, may different time scales should be examined to explore better practices.

Finally, as with all databases for CGE models, spatial and sector aggregation add difficulties in the application of models to disaster impact analysis, especially at the subnational level. Experience from past disasters suggests that damage even to a single semiconductor company can paralyze countrywide automobile production. This type of effect cannot be estimated by CGE models due to their macroeconomic nature, even when the most refined interindustry database is used. Regional aggregation has a similar problem, for example, with products from nondamaged companies in the same sector and region substituting for products from the damaged companies. In this case, the supply-chain effect is rarely observed. These shortcomings might be overcome by additional micro-trade analysis based on individual business trades. ${ }^{13}$

\section{Conclusions}

Herein we constructed an SCGE model to analyze the economic impacts of natural disasters. We examined several simulations with various parameter assumptions, particularly those for sectoral elasticities of substitution, were experimentally investigated to examine the comportability of model results with actual observation three months after the Great East Japan Earthquake of 2011.

Small elasticities of the substitution in interregional trade ( 0 for automobile parts and $1 / 3$ as the normal case for other sectors) were deemed "best" for short-run analyses. This produced the lowest RMSE between the estimated production levels and the observed IIPs, which was statistically smaller than similar residuals obtained from competitive models. Such a finding is consistent with the assumptions used for CGE models in previous research, but are validated here for the first time.

Assumptions of CGE models should continue to be investigated and updated via data for various time scales after disasters. Incorporating adaptation behavior in both the supply and demand is key to improving the model estimation accuracy in the short-run. Furthermore, there are other issues that have not been covered and discussed here that are important and should be addressed to improve all economic-loss estimation models. For example, we do not consider changes in consumption patterns, such as the increased ratios of consumer spending on durable and necessary goods after a disaster. Because CGE models are typically perceived as black boxes, it is necessary to systematically extend and validate them.

\section{Acknowledgements}

Eelier versions of this paper are presented at the $23^{\text {rd }}$ and $24^{\text {th }}$ International Input-Output Conferences. We thank participants as well as the editors and anonymous referees for their comments that improved our research.

\section{Funding}

This work was supported by MEXT-Japan [JSPS KAKENHI Grant Number 16H04427/16K12390 and the Program for Risk Information on Climate Change].

\section{References}

13 For example, Saito (2015) analyzed interfirm transaction data from 800,000 firms in Japan and investigated the key firms that can affect widespread disaster impacts, such as the Great East Japan Earthquake. 
Atkeson, A. and P.J. Kahoe (1999) Models of Energy Use: Putty-Putty Versus Putty-Clay. American Economic Review, 89, 1028-1043.

Badri, N.G., and T.L. Walmsley (2008) Global Trade, Assistance, and Production: The GTAP 7 Data Base. Center for Global Trade Analysis, Purdue University.

Bourguignon, F., G. Michel, and D. Miqueu (1983) Short-run Rigidities and Long-run Adjustments in a Computable General Equilibrium Model of Income Distribution and Development. Journal of Development Economics, 13, 21-43.

Cavallo, A., E. Cavallo and R. Rigobon (2013) Prices and Supply Disruptions during Natural Disasters, Working Paper 19474, National Bureau of Economic Research.

Dixon, P. B. and M. T. Rimmer. (2013) Validation in Computable General Equilibrium Modeling. Chapter 19 in P. B. Dixon and D. W. Jorgenson (eds.), Handbook of Computable General Equilibrium Modeling, Vol. 1B, Amsterdam, North-Holland, pp. 1069-1131.

Ghosh, A. (1958) Input-Output Approach in an Allocation System, Economica, 25, 58-64.

Giesecke, J.A., W.J. Burns, A. Barrett, E. Bayrak, A. Rose, P. Slovic, and M. Suher (2012). Assessment of the Regional Economic Impacts of Catastrophic Events: CGE Analysis of Resource Loss and Behavioral Effects of an RDD Attack Scenario. Risk Analysis, 32, 583-600.

Greenberg, M. R., M. Lahr and N. Mantell (2007) Understanding the Economic Costs and Benefits of Catastrophes and Their Aftermath: A Review and Suggestions for the U.S. Federal Government. Risk Analysis, 27, 83-96.

Hallegatte, S. (2008) An Adaptive Regional Input-output Model and Its Application to the Assessment of the Economic Cost of Katrina. Risk Analysis, 28, 779-799.

Hertel, T.W. (ed.) (1997) Global Trade Analysis: Modeling and Applications. New York, Cambridge University Press.

Ichioka, O. (1991) Applied General Equilibrium Analysis. Tokyo, Yuhikaku (In Japanese).

Johansen, L. (1959) Substitution versus Fixed Production Coefficients in the Theory of Economic Growth: A Synthesis. Econometrica, 27, 157-176.

Kajitani, Y, and H. Tatano (2014) Estimation of Production Capacity Loss Rate after the Great East Japan Earthquake and Tsunami in 2011, Economic Systems Research, 26, 13-38.

Koike, A., K. Ito, and T. Nakao (2012) Estimation of Armington Elasticities in Japan. Journal of Japan Society of Civil Engineering, 68, 55-61 (In Japanese).

Koks, E.E., and M. Thissen (2016). A Multiregional Impact Assessment Model for Disaster Analysis. Economic Systems Research, 28, 429-449.

Ministry of Economy, Trade and Industry (METI) (2010) 2005 Interregional Input-Output Table. Accessed 22 September 2014 http://www.meti.go.jp/statistics/tyo/tiikiio/result/result_02.html (In Japanese).

Nishinihon Shinbun. (2016) Why Did Toyota Recover Faster in 2016 Kumamoto Earthquake Than in the Great East Japan Earthquake ("Toyota, higashi nihon daishinsai yori fukkyu ga hayai riyuu ha?"), Nishinihon Shinbun Online, April 30 2016, available at http://qbiz.jp/article/86013/1/\# (last accessed 4 April 2017) (In Japanese).

Oosterhaven, J. (1988) On the Plausibility of the Supply-driven Input-output Model. Journal of Regional Science, 28, 203-217.

Oosterhaven, J. and M. C. Bouwmeester (2016) A New Approach to Modeling the Impact of Disruptive Events. Journal of Regional Science, 56, 583-595.

Okuyama, Y., G.J.D. Hewings and M. Sonis (2004) Measuring Economic Impacts of Disasters: Interregional Input-Output Analysis Using Sequential Interindustry Model. In: Y. Okuyama and 
S.E. Chang (eds.) Modeling Spatial and Economic Impacts of Disasters, New York, Springer, 77101.

Okuyama, Y. and J. R. Santos (2014) Disaster Impact and Input-Output Analysis. Economic Systems Research, 26, 1-12.

Okuyama, Y. and S.E. Chang (eds.) (2004) Modeling Spatial and Economic Impacts of Disasters. New York, Springer, pp. 13-36.

Partridge, M. D. and D.S. Rickman (1998) Regional Computable General Equilibrium Modeling: A Survey and Critical Appraisal. International Regional Science Review, 21, 205-248.

Robinson, S. (1989) Multisectoral model. In: Chenery, H. and T.N. Srinivasan (eds.), Handbook of Development Economics 2, Amsterdam, North-Holland, pp. 886-947.

Romanoff, E. and S. Levine (1986) Capacity Limitations, Inventory, and Time-phased Production in the Sequential Interindustry Model. Papers of the Regional Science Association, 59, 73-91.

Rose, A. and G. Guha (2004) Computable General Equilibrium Modeling of Electric Utility Lifeline Losses. In: Y. Okuyama and S.E. Chang (eds.) Modeling Spatial and Economic Impacts of Disasters, New York, Springer, pp. 119-141.

Rose, A. and S. Liao (2005) Modeling Regional Economic Resilience to Disasters: A Computable General Equilibrium Analysis of Water Service Disruptions. Journal of Regional Science, 45, 75112.

Saito, Y.U. (2015) Geographical Spread of Interfirm Transaction Networks and the Great East Japan Earthquake. In: T. Watanabe, I. Uesugi, and A. Ono (eds.) The Economics of Interfirm Networks. Tokyo, Springer Japan, pp. 157-173.

Shoven, J.B. and J. Whalley (1992) Applying General Equilibrium, Cambridge UK, Cambridge University Press.

Tatano, H. and Tsuchiya, S. (2008) A Framework for Economic Loss Estimation Due to Seismic Transportation Network Disruption: A Spatial Computable General Equilibrium Approach. Natural Hazards, 44, 253-265

Taylor, L. and F.J. Lysy (1979) Vanishing Income Redistributions: Keynesian Clues about Model Surprises in the Short Run. Journal of Development Economics, 6, 11-29.

Ueda, T. (ed.) (2010) Regional and Urban Economics Analysis with Excel. Tokyo, Corona (In Japanese). Wilcoxon, F. (1945) Individual Comparisons by Ranking Methods, Biometrics Bulletin, 1 (6): 80-83. 